\title{
History and Evolution of Epilepsy Surgery
}

\section{História e evolução da cirurgia para epilepsia}

\author{
Gustavo Passos ${ }^{10}$ \\ ${ }^{1}$ Department of Neurosurgery, Hospital de Clínicas da Universidade \\ Federal do Paraná, Curitiba, PR, Brazil \\ Arq Bras Neurocir 2020;39(1):27-32.
}

\begin{abstract}
Address for correspondence Gustavo Passos, MD, Departmento de Neurocirurgia, Hospital de Clínicas da Universidade Federal do Paraná, Travessa Lange, 277 - Apartamento 1301, 80240-170, Curitiba, PR, Brazil (e-mail: dr.gustavopassos@gmail.com).
\end{abstract}

\author{
Abstract \\ Keywords \\ - history \\ - epilepsy \\ - epilepsy surgery \\ - temporal lobe \\ - depth electrodes
}

\section{Resumo}

Palavras-chave

- história

- epilepsia

- cirurgia para epilepsia

- lobo temporal

- eletrodos profundos
The surgical treatment for epilepsy has a worldwide historical relevance for centuries. There are archaeological reports that date it back to ancient Egypt; however, the year 1886 is considered a landmark in the surgical treatment for epilepsy in the Modern Age, when the first surgery for the treatment of focal epileptic events was performed successfully. Since then, innumerable related articles have been published evoluonarily. Over the last centuries, new techniques and technologies provided better understanding, diagnosis and management for this disease. Thus, historical and evolutionary knowledge becomes important to let us better understand the current position of the surgery for epilepsy treatment and control.

A cirurgia para tratamento da epilepsia tem relevância histórica mundial há séculos. Há relatos arqueológicos que remontam ao Egito antigo; porém, é considerado marco no tratamento cirúrgico da epilepsia na Idade Moderna o ano de 1886, quando foi realizada com sucesso a primeira cirurgia para tratamento de crises epilépticas focais. Desde então, inúmeros relatos e artigos relacionados foram publicados. Evolutivamente, nos últimos séculos, novas técnicas e tecnologias nos propiciaram um melhor entendimento, diagnóstico e manejo desta enfermidade. Assim, torna-se importante o conhecimento histórico e evolutivo para que possamos compreender melhor a atual posição da cirurgia para tratamento e controle das epilepsias.

\section{Introduction}

Epilepsy was not always being recognized as a pathology of neurological origin. In the past, it was believed to be related to demonic spiritual possession; Thus, it is understood that trepanation was not always performed for medical purposes, because the religious or spiritual character initially prevailed. However, the goal was always the same, the attempt to put an end to epileptic seizures.

\section{Methodology}

The PubMed database was used as the primary source of research with the keywords epilepsy surgery history and epilepsy surgery evolution and advance. In addition, some books were consulted, including: Textbook of Epilepsy Surgery, edited by H. Lüders, ${ }^{13}$ and Operative Techniques in Epilepsy, edited by J. Girvin.

\section{Brief History of Epilepsy and its Surgical Treatment}

Trepanation (from the Greek trupanon, which means "perforating") is the removal of part of the cranial calvarium without causing lesions to the vessels, meninges, or the brain tissue itself under it. Cranial trepanation is described in manuscripts that date to before $1500 \mathrm{bC}$, and skulls from the Neolithic period ( 10000 to $4000 \mathrm{bC}$ ) were found with received

December 20, 2016

accepted

May 31, 2017
DOI https://doi.org/

10.1055/s-0037-1604029. ISSN 0103-5355.
Copyright (c) 2020 by Thieme Revinter

Publicações Ltda, Rio de Janeiro, Brazil
License terms

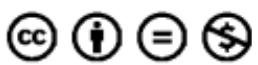


signs of trepanation. The earliest report of a successful neurosurgical procedure was obtained through a carbondated skull from 5100 bC, which was found in a French archaeological site. Evidence of bone healing at the edges of the wound shows that the skull is from the first patient who survived the trepanation procedure. ${ }^{1,2}$ Although it is not possible to know for certain. Why trepanation may have been performed to relieve intracranial pressure? Elevate fractures with cranial sinking? To remove bone fragments caused by penetrating trauma. It is known as a procedure that has been performed with different purposes since prehistoric times. ${ }^{3,4}$ Historically, it was performed in the Middle and Far East, among Celtic tribes, among the Mayas, Incas, Aztecs and Brazilian Indians; it was very common in the Middle Ages and Equatorial Africa, where it is still performed today. $^{5-8}$

The first description of epilepsy as a disease can be found in the Corpus Hippocraticum, a collection composed of 60 treaties dating to $400 \mathrm{bC}$, in Ancient Greece. Then, epilepsy was a controversial disease, often associated with possessions, genius and divinity, being even called the "sacred disease." It is in this book that Hippocrates, for the first time, talks about the hypothesis that epilepsy is located in the brain, and is not a disease of sacred origin. It would be caused by an excess of phlegm in the brain, which, when in contact with the blood, would cause epileptic seizures. ${ }^{9}$ But the word epilepsy would be used for the first time by Avicenna (980-1037), a Persian polymath who wrote countless treaties on different subjects, 40 of them focused on medicine. The word derives from the Greek verb epilambanein, which means to be taken, attacked or dominated.

The age of epileptology, stricto sensu, began in 1861, when John Hughlings Jackson (1835-1911), the founder of "modern epileptology," correlated convulsive crises with a cerebral dysfunction. In the following years, new hypotheses were made, until in 1870 its concept changed: the crises would originate in the cerebral cortex. ${ }^{10,11}$

Studying unilateral motor crises, Jackson could conclude that the motor cortex, and not isolated muscles, as it was thought before, was responsible for limb movements. This idea was confirmed by research with cortical stimulation in animals performed by neurologist David Ferrier (1843-1928).

One of the first topographic maps of the somatotropic organization of the motor cortex was idealized and published by Fedor Krause in 1911. Wilder Penfield (1891-1976) perfected the technique, resulting in the famous homunculus of Penfield, a map with a cortical representation of motor and sensory functions. A more modern example of cortical topographic representations of specific functions is the work by Ojemann, which shows the cortical variant of human speech.

The transition from cranial surgery to brain surgery occurred between the second half of the 18th century and the first half of the 19th century, when the idea that epilepsy could be caused by a disorder originating in the cerebral cortex was established. ${ }^{12}$ The transition from the pre-modern era (cranial surgery) to the modern era (brain surgery) occurred with the growing critical knowledge about trepanation, in association with the emerging theory of the somatotropic location of the brain areas, and the not less important evolution of asepsis and pain control during surgical procedures.

Epilepsy surgery was initially based on the visual identification of cortical lesions, usually of traumatic origin, and trepanations or trephine were used for the surgical access.

1886 marks the beginning of the contemporary age of epilepsy surgery, when the first surgeries were performed, aiming at the treatment of epileptic seizures in three patients. Sir Victor Horsley (1857-1916) was the neurosurgeon responsible for the surgeries performed in London. Victor Horsley and William MacEwen (1848-1924), from Glasgow, who at the same time also initiated the surgical treatment of patients with epilepsy, are considered the founders of British neurosurgery. In the same period, neurosurgeon Fedor Krause initiated the surgery for epilepsy in Germany. In the aforementioned procedures, there was collaboration between neurologists and neurosurgeons in the United Kingdom, with Hughlings Jackson, and in Germany, with Hermann Oppenheim (1858-1919) -, which became indispensable for the success of the proposed surgeries. ${ }^{13,14}$ Such events served as the basis for the formation of multidisciplinary groups for the treatment of epilepsy; however, in the second half of the 20th century, most of the centers specialized in epilepsy treatment introduced the joint model, with the collaboration of neurologists, neurosurgeons, neuroradiologists and neuropsychologists.

The scientific evolution and the increasingly concrete idea of achieving success in the control of epileptic seizures through surgery spread quickly throughout the world in the end of 19th century and early 20th century. With this, many countries all over the world began to devote resources to the development and research in this area. It is important to remember that, during this period, the surgeries performed for epilepsy control were mostly directed to epilepsy due to trauma or tumors. Until the 1920s, the surgeries were only performed for chronic and localized epilepsy, and the knowledge at the time allowed the physicians to program the region to be operated based only on the semiology and detailed clinical observation of the patients seizure. During surgery, the physicians needed to identify visually the cortical anatomical alterations to be resected, and they often used cerebral electrical stimulation to detect the motor area and the central sulcus, because electroencephalography (EEG) and electrocorticography (ECoG) were not yet available.

With the discovery of X-rays, in 1895, by German physicist Wilhelm Conrad Röntgen (1845-1923), pneumoencephalography, in 1919, by Walter Dandy (1886-1946), and cerebral arteriography, in 1927, by Portuguese neurologist and researcher Egas Moniz (1874-1955), there was a major breakthrough on epilepsy surgery, which enabled physicians to recognize the etiology and topography of the causes preoperatively using images. But it was only in 1929 that German neuropsychiatrist Berger (1873-1941) described the invention and application of the human electroencephalogram, which enabled the recognition of patterns associated with epilepsy and the location of areas with epileptogenic cerebral tissue. Thus, the use of electrophysiological knowledge in epilepsy surgery began, providing elements to aid in the 
diagnosis and to determine the cerebral area to be resected prior to the surgical procedure. ${ }^{15}$

In 1934, the Montreal Neurological Institute, in Canada, was founded. Conceived by Wilder Penfield in conjunction with the McGill University, it was a hybrid and unique project for the time, with a hospital area for patients with neurological disorders, a research center totally focused on the nervous system, and a department of neurology and neurosurgery at the university. Penfield, who had great interest in epilepsy treatment, conducted his studies after getting excited about the data collected by pioneer Victor Horsley, and obtained neurosurgical training with Harvey Williams Cushing (1869-1939), who is recognized as the father of modern neurosurgery, and who had already performed surgeries under local anesthesia in patients with epilepsy. Cushing was the first to report the mapping of the sensory cortex with the aid of cortical electrostimulation. However, Cushing was mainly devoted to the study and treatment of brain tumors. $^{16,17}$

In 1937, Canadian neurologist Herbert Jasper (19061999) joined the Montreal Neurological Institute. With his previous experience in EEG and with the electrographic foundations of the epilepsies already established, Jasper developed ECoG, which made it possible to map the location of the epileptic seizures during surgery, recording directly from the cerebral cortex and monitoring the responses of stimulation, thus delimiting the area to be resected with greater precision. In that same year, with the aid of intraoperative cortical stimulation and its motor findings, Penfield and Boldrey published for the first time the illustration of what would be perfected and then recognized, 11 years later, as the Homunculus (by Penfield and Rasmussen).

In followinf years, there was great development and many researches in the field of epilepsy, and the surgical treatment evolved along with that. The evolutionary progress and knowledge of the anatomopathology and the electroencephalographic parameters enabled the performance of surgeries totally based on the interictal EEG, according to the publication by Bailey and Gibbs, ${ }^{19}$ in 1951, reporting the work with a series of patients with temporal lobe epilepsy undergoing surgical resection. ${ }^{18,19}$ Concomitantly, the publications of Penfield, Jasper and other collaborators of the Montreal Institute presented their series of patients with temporal lobe epilepsy undergoing surgical ablation, their electroencephalographic alterations, and their results regarding crisis control. ${ }^{20-22}$

Thus, in the 1950s, there was a major worldwide spread of the surgery for epilepsy, mainly of procedures aimed at the resection of the temporal lobe. Surgeries unrelated to resections of lesions determined visually were initiated, but they were guided by clinical findings and preoperative electrophysiological exams. ${ }^{23,24}$

In 1953, Murray Falconer (1910-1977) published in London the technical standards for anterior resection of the temporal lobe, en bloc, which contributed to the research and development of the pathological bases involved in temporal lobe epilepsy. The results showed that a large number of patients with temporal lobe epilepsy had hippocampal sclerosis, which boosted the research and investigation of the pathological hippocampus and the relationship between hippocampal sclerosis and temporal lobe epilepsy. ${ }^{25-27}$

Bouchet and Cazauvieilh were the first to describe, in the early 19th century, the presence of hippocampal sclerosis in patients with epilepsy. However, whether this would be the cause or effect of epilepsy was still under debate until the 1960 s, when it was possible to understand that this was an epileptogenic alteration.

In Brazil, the onset of the surgical treatment for epilepsy dates to the 1950s, and the most striking and pioneering contribution was by neurosurgeon Paulo Niemeyer Soares (1914-2004), who worked at Santa Casa da Misericórdia do Rio de Janeiro. Paulo Niemeyer was the first to propose and publish the amygdalohippocampectomy by transventricular access for the treatment of temporal lobe epilepsy in 19571958 , with expressive results in crisis control. ${ }^{28}$ This technique was accepted and is still used in many specialized centers. The first program aimed at epilepsy surgery in Brazil was established in the 1970s, at Universidade de São Paulo, by neurosurgeon Raul Marino Júnior.

Still in the 1950s, in Switzerland there was also a clear increase in the number of surgeries for epilepsy with Hugo Krayenbühl (1902-1985), who initiated and coordinated the department of neurosurgery at the University of Zurich. ${ }^{29}$ At the same time, professor Krayenbühl was already performing a standardized technique for temporal lobectomy. One of his pupils - Mahmut Gazi Yasargil -, after researching and familiarizing himself with surgical microscopy, initiated, in 1969, the era of neurological microsurgery, designing and reinventing materials. Subsequently, Yasargil published a description of a microneurosurgical technique known as selective amygdalohippocampectomy, which consisted of the removal of the temporal medial basal structures using a transsylvian access, without the need for the removal of the anterior part of the temporal lobe. ${ }^{30-32}$ This technique is used worldwide up to this days in many specialized centers for epilepsy surgery. After the introduction of the surgical microscope, several new techniques for epilepsy developed internationally.

The understanding and application of EEG and neurophysiology grew progressively, and, with this, the idea of establishing a preoperative diagnosis for an increasingly precise surgical planning caused variations and improvements to emerge in electroencephalographic monitoring. ${ }^{33-35}$ New kinds of surface electrodes for EEG were developed, and the idea of obtaining information directly from the cerebral cortex with the subdural electrodes, already described in the 1940s, became widely used and disseminated in the following decades with the publications by Penfield and Jasper in Montreal. ${ }^{36,37}$

With the technological evolution and the advent of video in the EEG, prolonged electrophysiological monitoring became possible, facilitating the semiologic investigation of seizures. ${ }^{38-40}$

Following the idea of detecting the precise cerebral site involved with the onset of and to then proceed with surgical removal, and thus obtain the cure for epilepsy, French neurologist Jean Bancaud (1921-1993) postulated a way to monitor different areas and brain structures during a seizure, rather than using interictal encephalographic findings. 
Bancaud and neurosurgeon Jean Talairach (1911-2007) were the first, between the 1950s and 1960s, in Paris, to describe in detail the implantation of deep cerebral electrodes with the aid of the device and coordinates of stereotaxy developed by Talairach, which is recognized as the founder of modern stereotaxy. In 1962, the technique was named stereoelectroencephalography (SEEG), and it would be the best way to correlate the semiology of the crisis with the anatomical temporal distribution obtained, and thus localize the ictal onset zone and the epileptiform dissemination network involved. In addition, there would be the possibility of cerebral stimulation, and thus of creating a three-dimensional model for investigation. The SEEG would be used in the preoperative evaluation of patients who are candidates for epilepsy surgery in France. ${ }^{41-43}$

Neuropsychology was extensively studied in the 1950s and 1960s, and it represents an evolution in epilepsy surgery. Brenda Milner (1918) and Juhn Wada (1924) were important researchers in this field, and they were able to collaborate with studies relating memory and language with mesial temporal resection in patients with temporal lobe epilepsy. Dr. Juhn Wada introduced and demonstrated the intracarotid use of sodium amobarbital to determine the cerebral dominance for the language function, the Wada test, as an important part of the preoperative study. Milner developed the basis of some neuropsychological tests that are still used today, and expanded the use of the Wada test to evaluate the functional memory reserve of patients undergoing surgical treatment for epilepsy. Penfield was the first to report and advocate the use of a multiprofessional group to perform the pre- and postoperative assessments, to better discriminate the pathological brain area with its psychological alterations and thus predict possible memory and language deficits with surgical treatment, besides being able to identify the presence of the cortical reorganization of cognitive functions. This was all to better guide the type and extent of resection to be performed in patients. ${ }^{44-47}$

From the 1970s onwards, with the establishment of the anatomopathological, electrophysiological and neuropsychological knowledge acquired, and the surgical results obtained in previous years, associated with the invention of computed tomography (CT) and other imaging methods, there was a grand global expansion in the surgical treatment of refractory epilepsies. The possibility of visualizing images of the human brain in three dimensions - and identifying structural lesions located in many patients with focal epilepsy, until then diagnosed as cryptogenic epilepsy - marked the onset of modern neuroimaging. The association of neuroimaging and EEG findings led us once again to surgeries based on directly visualized lesions, but now with preoperative visualization and electrophysiological correlation of the lesion with the crises. The CT quickly replaced the X-rays and pneumoencephalography, because it was much more sensitive in the detection of tumors, vascular lesions, posttraumatic alterations and infecto-inflammatory diseases. ${ }^{48}$

In the 1980s, magnetic resonance imaging (MRI) was introduced for the clinical practice, causing a revolution in several fields of medicine, and quickly replaced the CT in the diagnostic evaluation of epilepsies, as it demonstrated anatomical structures and cerebral pathologies in more detail.

With the technological evolution, new sequences of images were being made available, and new techniques to define the morphology and volume of deep brain structures were developed. Currently, it is estimated that $\sim 70 \%$ of patients with focal epilepsy evaluated in specialized centers present alterations in MRI images. ${ }^{49,50}$ With the evolutionary improvement of image quality in higher magnetic field devices, there was the possibility of identifying unrecognized lesions and to estimate anatomical alterations in a noninvasive way.

Still during the 1980s, new exams, not only imaging but functional exams, were developed and added to the preoperative diagnostic arsenal of epilepsies. Among them, there is positron emission tomography (PET), which uses a radiopharmaceutical, fluorodeoxyglucose, marked with fluoride 18 (18F-FDG),injected intravenously in the patient, to observe its distribution in the brain, detected by tomography. In the interictal period, there is a hypometabolism in the pathological area and a hypermetabolism in the ictal phase. In a correlated manner, single-photon emission computed tomography (SPECT) was developed, which uses technetium-99m as a radiopharmaceutical and presents an interictal hypometabolism and a hypermetabolism during the ictus. ${ }^{51,52}$

With these new forms of functional metabolic investigation, patients who did not have visible lesions in the MRI could be topographically diagnosed and, in conjunction with the video-electrographic findings, selected for surgical treatment. The aim of performing a high-quality and precise preoperative evaluation resulted in the development of new techniques that improved the safety and outcome of surgeries. ${ }^{53,54}$

In the 1990s, there was the introduction of functional nuclear magnetic resonance (fNMR). This technique explores the dependent effect on the blood oxygenation level, and ,in brain areas activated with specific functions, the percentage of deoxyhemoglobin is reduced compared with non-active areas, which generates an increase in the signal in the T2weighted images, enabling a cerebral mapping.

The use of fNMR in memory and language areas is important in the programming of patients with refractory epilepsy selected for surgery. ${ }^{55}$

It is currently possible to obtain images of the interictal activity using EEG and fNMR together. The white matter and the connectivity of the tracts became visible with the introduction and evolution of tractography. This technology has contributed to the precise definition of the epileptiform zone, its connections and its relationship with eloquent areas.

Another recently available variant is subtraction ictal SPECT coregistered to MRI (SISCOM), which enables the fusion of the ictal SPECT image with the high-resolution images of the morphological MRI. Equally important for the non-invasive diagnosis of ictal focus is magnetoencephalography, the three-dimensional reconstruction of the interictal EEG tracing captured by countless surface electrodes fused with the three-dimensional images of the morphologic MRI. These more precise diagnostic techniques are specifically important in the so-called non-injured cases, that is, patients 
refractory to medications, with no identifiable lesions in the MRI.

After the development of the MRI and its technological evolution, small congenital cerebral alterations could be identified and correlated with the primary ictal zone. The improvement and refinement of microsurgical techniques, and the knowledge and development in computer graphics with the use of neuronavigation associated with intraoperative MRI increased the success rates of the surgical procedures for epilepsy. ${ }^{56}$

The final decade of the 20th century was remarkable in the evolution of the surgery for epilepsy. In the 1980s, most of the surgery groups for epilepsy used basically one surgical technique for the approach, depending on the place where the surgeons were trained. In 1986, the first conference on epilepsy surgery was held in California, which managed to bring together almost all of the centers specialized in epilepsy in the world to present and compare their techniques and their results. In the years that followed, countless new publications and new specialized centers emerged, and most centers innovated and adapted different techniques for the treatment of different types of epilepsy. In the beginning of the 1990s, most of the world centers were already conducting research with deep cerebral electrodes and encephalographic recordings with subdural electrodes, and performing surgeries in many patients based only on the high-quality non-invasive investigation.

At the beginning of the 21st century, the first randomized controlled scientific studies that demonstrated the superiority of the surgical treatment in patients with temporal lobe epilepsy without drug control were published, confirming the already established consensus that surgery would be the best treatment for refractory epilepsies. ${ }^{57}$

Currently, the use of all available resources by a multidisciplinary group dedicated specifically to the surgical treatment of epilepsy is indispensable to make an accurate diagnosis, to precisely identify the primary ictal zone, and to perform the specific resection of this cerebral area, to obtain the highest rate of seizure control with the lowest risk of functional deficits.

\section{Conflict of Interests}

The authors have no conflict of interests to declare.

\section{References}

1 Clower WT, Finger S. Discovering trepanation: the contribution of Paul Broca. Neurosurgery 2001;49(06):1417-1425, discussion 1425-1426

2 Finger S, Clower WT. On the birth of trepanation: the thoughts of Paul Broca and Victor Horsley. In Arnott R, Finger S, Smith CUM, (eds). Trepanation History, Discovery, Theory. Lisse, The Netherlands: Swets \& Zeitlinger; 2003:19-42

3 Epstein JA. Ancient skull surgery.J Neurosurg 1992;77(04):657-658

4 Lillie MC. Cranial surgery dates back to Mesolithic. Nature 1998; 391(6670):854

5 Froeschner EH. Two examples of ancient skull surgery. J Neurosurg 1992;76(03):550-552

6 Horsley V. Trephining in the neolithic period. J Anthropol Inst G B Irel 1888;17:100-106
7 Lisowski FP. Prehistoric and Early Historic Trepanation. In: Diseases in Antiquity. eds. Bothwell D, Sandison AT. Charles Thomas; 1967: 651-672

8 Meador KJ, Loring DW, Flanigan HF. History of Epilepsy surgery. J Epilepsy 1989;2:21-25

9 Temkin O. The Falling Sickness - A History of Epilepsy from the Greeks to the Beginnings of Modern Neurology, 2nd ed. Baltimore and London: Johns Hopkins University Press; 1971

10 Jackson JH. A study of convulsions. Arch Neurol 1970;22(02): 184-188

11 Jackson JH. On the anatomical, physiological, and pathological investigation of the epilepsies. West Riding Lunatic Asylum Med Rep 1873;3:15-19

12 Taylor DC. One hundred years of epilepsy surgery: Sir Victor Horsley's contribution. In: Surgical Treatment of the Epilepsies. edited by Engel J Jr. New York: Raven Press; 1987:7-11

13 Wolf P. The history of surgical treatment of epilepsy in Europe. In: Epilepsy surgery. edited by Hans Lüders. Raven Press Ltd; 1991:9-17

14 Meador KJ. Beginnings of the modern era of epilepsy surgery. Arch Neurol 1999;56(05):629-630

15 Cooke J. History and method of Cure of the various species of epilepsy. London: Longman, Hurst, Rees, Orme and Brown; 1823: 194

16 Penfield W, Flanigin H. Surgical therapy of temporal lobe seizures. AMA Arch Neurol Psychiatry 1950;64(04):491-500

17 Penfield W, Baldwin M. Temporal lobe seizures and the technic of subtotal temporal lobectomy. Ann Surg 1952;136(04):625-634

18 Gibbs FA, Gibbs EL, Lennox WG. Cerebral dysrhythmias of epilepsy. Arch Neurol Psychiatry 1938;39:298-314

19 Bailey P, Gibbs FA. The surgical treatment of psychomotor epilepsy. J Am Med Assoc 1951;145(06):365-370

20 Jasper $\mathrm{H}$, Kershman J. Electroencephalographic classification of the epilepsies. Arch Neurol Psychiatry 1941;45:903-943

21 Jasper H, Pertuisset B, Flanigin H. EEG and cortical electrograms in patients with temporal lobe seizures. AMA Arch Neurol Psychiatry 1951;65(03):272-290

22 Morris AA. The surgical treatment of psychomotor epilepsy. Med Ann Dist Columbia 1950;19:121-131

23 Greenblatt SH. Cerebral localization: from theory to practice; Paul Broca and Hughlings Jackson to David Ferrier and William MacEwen. In: Greenblatt SH (ed.). A History of Neurosurgery. AANS Park Ridge; Ill.1997:137-152

24 Lyons AE. The crucible years 1880 to 1990 ; Macewen to Cushing. In Greenblatt SH (ed.). A History of Neurosurgery. AANS Park Ridge; Ill.1997:153-166

25 Falconer MA, Taylor DC. Surgical treatment of drug-resistant epilepsy due to mesial temporal sclerosis. Etiology and significance. Arch Neurol 1968;19(04):353-361

26 Falconer MA. Discussion on the surgery of temporal lobe epilepsy: Surgical and pathological aspects. Proc R Soc Med 1953; 46:971-974

27 Falconer MA, Meyer A, Hill D, Mitchell W, Pond DA. Treatment of temporal-lobe epilepsy by temporal lobectomy; a survey of findings and results. Lancet 1955;268(6869):827-835

28 Niemeyer $\mathrm{P}$. The transventricular amygdalohippocampectomy in temporal lobe epilepsy. In: Baldwin M, Bailey P (eds.). Temporal Lobe Epilepsy 461-82. Charles C ThomasSpringfield, Ill1958

29 Krayenbühl H. The place of microsurgical technique in neurological surgery. The Fifth Sir Hugh Cairns Memorial Lecture. 79th Meeting, British Society of Neurological Surgeons. London (UK); 1969

30 Yasargil MG. Microsurgery Applied to Neurosurgery. Stuttgart: Thieme Verlag; 1969

31 Engel J Jr. The emergence of neurosurgical approaches to the treatment of epilepsy. In: Waxman S (ed.). From Neuroscience to Neurology: Neuroscience, Molecular Medicine, and the Therapeutic Transformation of Neurology. Amsterdam: Elsevier; 2005: 81-105 
32 Wieser HG, Yaşargil MG. Selective amygdalohippocampectomy as a surgical treatment of mesiobasal limbic epilepsy. Surg Neurol 1982;17(06):445-457

33 Bates J. Special investigation techniques - indwelling electrodes and electrocorticography. In: Hill D, Parr G (eds.). Electroencephalography. London: MacDonald; 1963:429-479

34 Delgado JM. Permanent implantation of multilead electrodes in the brain. Yale J Biol Med 1952;24(05):351-358

35 Delgado JM, Hamlin H, Chapman WP. Technique of intracranial electrode implacement for recording and stimulation and its possible therapeutic value in psychotic patients. Confin Neurol 1952;12(5-6):315-319

36 Gibbs F, Lennox W, Gibbs E. The electroencephalogram in diagnosis and localization of epileptic seizures. Arch Neurol Psychiatry 1936;36:1225-1235

37 Gibbs FA, Davis H, Lennox WG. The electroencephalogram in epilepsy and in conditions of impaired consciousness. Arch Neurol Psychiatry 1935;34:1133-1148

38 Liberson WT, Smith RW. The use of an FM tape recorder for pen and ink recording of fast EEG and EMG frequency components. Electroencephalogr Clin Neurophysiol 1955;7(04):649-652

39 van Leeuwen WS, Kamp A. Radio telemetry of EEG and other biological variables in man and dog. Proc R Soc Med 1969;62(05): 451-453

40 Ives JR, Gloor P. A long term time-lapse video system to document the patients spontaneous clinical seizure synchronized with the EEG. Electroencephalogr Clin Neurophysiol 1978;45(03):412-416

41 Talairach J, De Aljuriaguerra J, David M. [A stereotaxic study of the deep encephalic structures in man; technic; physiopathologic and therapeutic significance]. Presse Med 1952;60(28):605-609

42 Bancaud J, Talairach J, Schaub C. Stereotaxic functional exploration of the epilepsies of the supplementary areas of the mesial surface of the hemisphere. Electroencephalogr Clin Neurophysiol 1962;14:788

43 Talairach J, Bancaud J, Bonis A, Szikla G, Tournoux P. Functional stereotaxic exploration of epilepsy. Confin Neurol 1962;22:328-331

44 Milner B, Penfield W. The effect of hippocampal lesions on recent memory. Trans Am Neurol Assoc 1955-1956;80(80th Meeting):42-48
45 Milner B, Branch Ç, Rasmussen T. Study of short term memory after intracarotid injection of sodium amytal. Trans Am Neurol Assoc 1962;87:224-226

46 Wada J, Rasmussen T. Intracarotid injection of sodium amytal for the lateralization of cerebral speech dominance. 1960. J Neurosurg 2007;106(06):1117-1133

47 Wada J. A new method for determination of the side of cerebral speech dominance. A preliminary report on the intracarotid injection of Sodium Amytal in man. Igaku To Seibutsugaku 1949;14:221-222

48 Gastaut H, Gastaut JL. Computerized transverse axial tomography in epilepsy. Epilepsia 1976;17(03):325-336

49 Sperling MR, Wilson G, Engel J Jr, Babb TL, Phelps M, Bradley W. Magnetic resonance imaging in intractable partial epilepsy: correlative studies. Ann Neurol 1986;20(01):57-62

50 McLachlan RS, Nicholson RL, Black S, Carr T, Blume WT. Nuclear magnetic resonance imaging, a new approach to the investigation of refractory temporal lobe epilepsy. Epilepsia 1985;26(06):555-562

51 Chugani HT, Shewmon DA, Peacock WJ, Shields WD, Mazziotta JÇ, Phelps ME. Surgical treatment of intractable neonatal-onset seizures: the role of positron emission tomography. Neurology 1988;38(08):1178-1188

52 Koepp MJ, Woermann FG. Imaging structure and function in refractory focal epilepsy. Lancet Neurol 2005;4(01):42-53

53 Theodore WH, Dorwart R, Holmes M, Porter RJ, DiChiro G. Neuroimaging in refractory partial seizures: comparison of PET, CT, and MRI. Neurology 1986;36(06):750-759

54 Lee BI, Markand ON, Wellman HN, et al. HIPDM single photon emission computed tomography brain imaging in partial onset secondarily generalized tonic-clonic seizures. Epilepsia 1987;28(03):305-311

55 Powell HW, Koepp MJ, Richardson MP, Symms MR, Thompson PJ, Duncan JS. The application of functional MRI of memory in temporal lobe epilepsy: a clinical review. Epilepsia 2004;45 (07):855-863

56 Engel J Jr. Surgery for seizures. N Engl J Med 1996;334(10):647-652

57 Jackson GD, Berkovic SF, Tress BM, Kalnins RM, Fabinyi GÇ, Bladin PF. Hippocampal sclerosis can be reliably detected by magnetic resonance imaging. Neurology 1990;40(12):1869-1875 